\title{
Accessory Tendon and Tripartite Insertion Pattern of Fibularis Longus Muscle. A Case Report
}

\author{
Tendón Accesorio y Padrón de Inserción Trifurcada del Músculo Fibular Largo. Reporte de Caso \\ Jayakumari, S.; Suri, R. K.; Rath, G \& Arora, J.
}

\begin{abstract}
JAYAKUMARI, S.; SURI, R. K.; RATH, G. \& ARORA, J. Accessory tendon and tripartite insertion pattern of fibularis longus muscle. A case report. Int. J. Morphol., 24(4):633-636, 2006.

SUMMARY: The fibular muscles are the chief everters of foot and play an important role in stabilizing its subtalar motion. In the present case detected incidentally, we report a case of an accessory tendon and tripartite insertion pattern of fibularis longus muscle in the left leg, out of which two slips were attached to plantar and lateral aspects of base of first metatarsal and the third slip was found blending with first dorsal interosseous muscle. Awareness and precise knowledge of such anatomical variants are important to surgeons performing reconstructive procedures.
\end{abstract}

KEY WORDS: Fibularis longus muscle; Accessory tendon; Tripartite insertion.

\section{INTRODUCTION}

The variations of the lateral compartment muscles of the leg is not uncommon in human beings (Hecker, 1923). A number of fibular accessory muscles have been noticed, which may be due to the result of the process of human evolution (Wachter \& Beekman, 1983). The origin of flexor digiti minimi and fibularis accessorius muscles from fibularis longus muscle has been reported (Bergman, 2005).Variant types of insertions of fibularis longus muscle have also been discussed (Sammarco \& Brainard 1991). The accessory fibularis muscle tendon is an excellent source of tissue for reconstruction of the fibular retinaculum (Mick, 1987).

In the present study, the anatomical disposition of fibularis longus muscle was found to be unusual. Therefore an attempt has been made to study its morphological details and to create an awareness about anatomical variations of fibular tendons which is clinically relevant to surgeons undertaking reconstructive procedures in the leg and foot.

\section{CASE REPORT}

An anomalous insertion pattern of fibularis longus muscle associated with an accessory tendon was encountered in the left leg of a 40 years old male cadaver during routine educational dissection of the lower limb. The disposition and attachments of peroneal muscles (longus and brevis) were studied and appropriate photographs were taken.

The peroneus longus and brevis originated in the form of a fused mass from the upper half of lateral surface of fibula. However, at the middle third of leg, the two muscles were separated. The tendon of fibularis brevis muscle displayed usual disposition and insertion into base of fifth metatarsal bone. An accessory tendon of fibularis longus muscle was noticed emerging from the fused mass of fibularis longus and brevis muscles in the middle third of leg and this tendon joined the main tendon of fibularis longus muscle obliquely, $2.3 \mathrm{~cm}$ proximal to the tip of lateral malleolous. This accessory tendon of fibularis longus muscle also received some muscle slips of fibularis brevis muscle on the posterior aspect (fig.1). The main tendon of fibularis longus muscle was inserted on the lateral side of base of first metatarsal bone and also gave off two additional slips (lateral and medial) (Fig 2 ). The lateral slip was seen blending with the first dorsal interosseous muscle whereas the medial slip was inserted on the plantar aspect of base of first metatarsal bone. Thus, the fibularis longus muscle displayed tripartite manner of insertion. Although the morphology of fibularis longus muscle was unusual, it received innervation from the superficial fibular nerve. The right leg displayed the normal arrangement and attachments of peroneal tendons. 


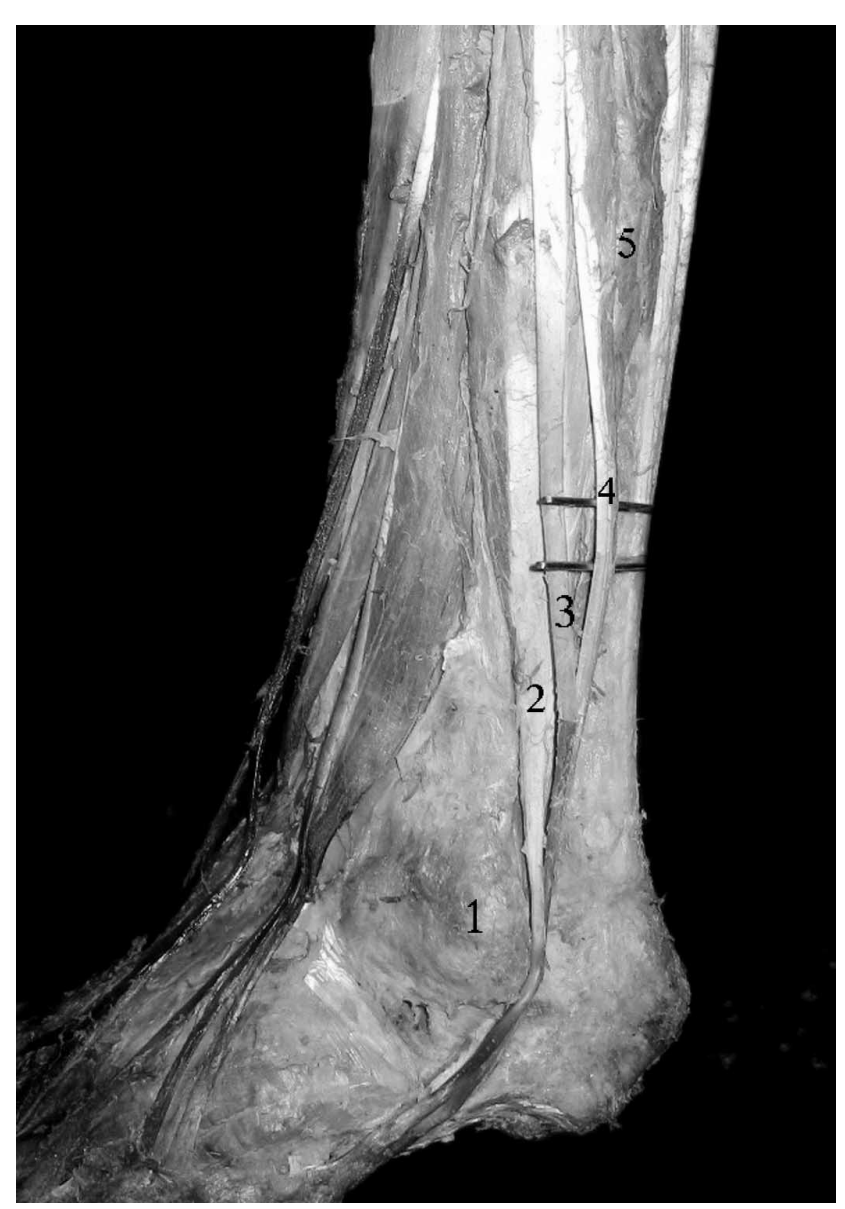

Fig. 1. Dissection of left leg showing the peroneal compartment muscles. 1. Lateral malleolus; 2. Fibularis brevis tendon; 3. Fibularis longus tendon; 4. Accessory tendon of fibularis longus; 5. Fibularis brevis muscle fibers.

\section{DISCUSSION}

The fibularis longus muscle originates from the head and proximal two-thirds of the fibula; while thefibularis brevis muscle originates from the distal two-thirds of the fibula. Both these muscles have a musculo tendinous portion that traverses just below the lateral malleolus. The fibularis longus muscle is inserted into the base of first metatarsal and medial cuneiform, whereas the fibularis brevis muscle is inserted into fifth metatarsal bone (Standring, 2005). The literature revealed that the variation in the fibular compartment muscles range from $13 \%$ to $20 \%$ (Goss, 1973). The fourth fibularis muscle as member of a group of accessory fibular muscles has been described as to be unique to humans (Henle, 1871). This supernumerary muscle originates as a slip high up on the fibula between the longus and brevis fibular muscles or from distal part of leg and the

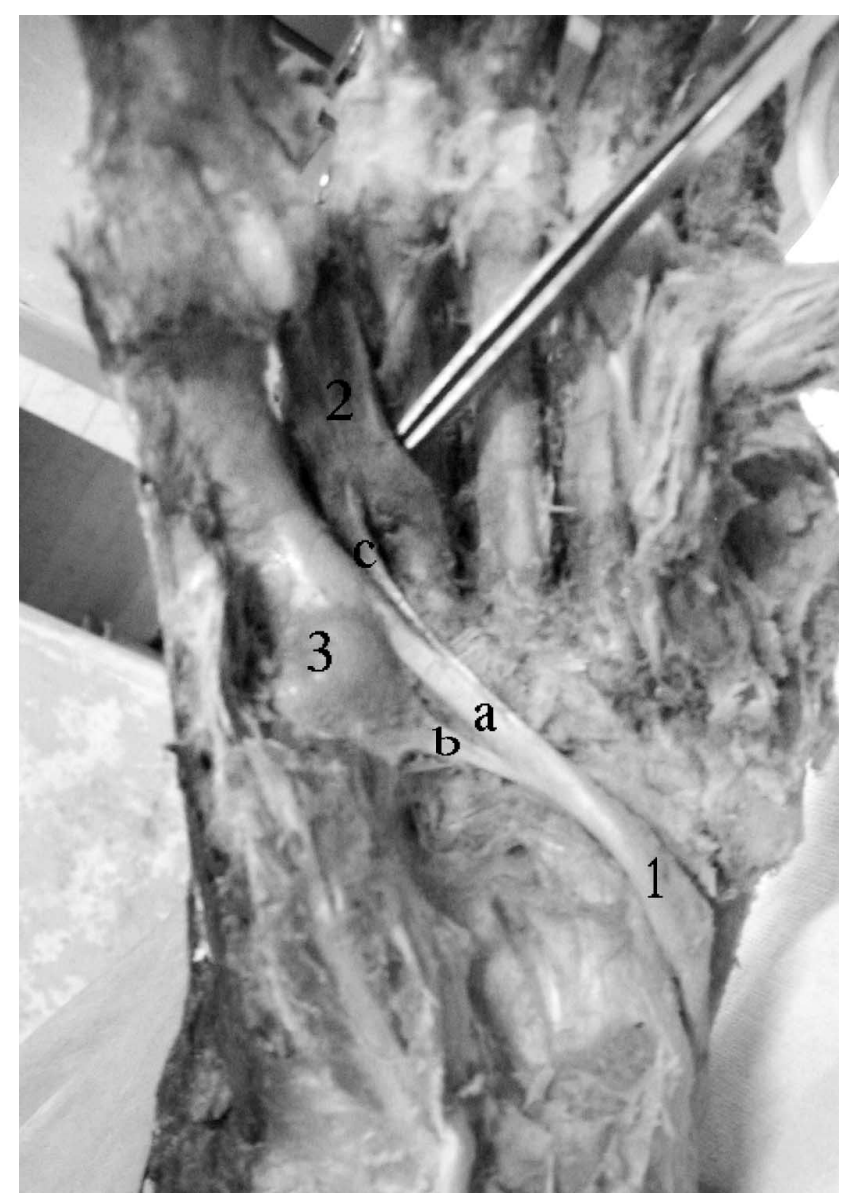

Fig. 2. Dissection of left sole showing the insertion of fibularis longus muscle. 1. Fibularis longus tendon. a) Main slip of insertion. b) Medial slip of insertion. c) Lateral slip of insertion; 2. First dorsal interosseous muscle; 3 . Base of first metatarsal bone.

distal attachments of the muscle are not fixed (Macalister, 1875; Hecker; Sobel, 1990).The origin of the fibularis quartus from the posterior aspect of the fibula between the brevis and flexor hallucis longus muscles was described (Wachter \& Beekman). The fibularis quartus muscle represents an evolutionary step in the development of bipedal posture (Hecker).

In the present study an accessory tendon originated from the fused fibular muscles (longus and brevis ) and this tendon joined the main tendon of fibularis longus muscle just proximal to lateral malleolous. Interestingly, the presence of this additional tendon joining the main tendon of fibularis longus muscle obliquely is a rare finding and this can probably alter the biomechanics of fibular muscles. 
The insertion of the tendon designated as peroneo peroneus longus has been reported earlier that described the variations with its insertion into fibularis longus muscle in sole (Hecker). The insertion of fibularis longus muscle as three tendinous slips to fifth, third and first metatarsal bones respectively has been described and occasionally one of the slip was attached to intermediate cuneiform bone (Macalister). However, in our study contrary to an earlier report, none of the three slips was inserted into cuneiform bone. In another research report, the tendon of fibularis longus muscle was found dividing into two equal parts; one was inserted into the lateral side of base of first metatarsal and medial cuneiform bone in the usual manner; other into tuberosity of the fifth metatarsal bone (Harbeson, 1937). A slip from the tendon of fibularis longus joining the first dorsal interosseous muscle in the present study is an observation that is quite consistent with an earlier report describing the origin of medial head of first dorsal interosseous muscle by means of a tendinous slip from the fibularis longus tendon (Harbeson,1933).

It also needs to be mentioned that as a consequence to anomalous arrangement in the present study the three fibular tendons are seen just proximal to lateral malleolus. The use of an accessory tendon obviates the sacrifice or weakening of a tendon that is used for routine function of the foot and the ankle (Mick). Injuries to the fibular tendons are commonly misdiagnosed as a lateral ankle sprain.It might be tendinitis, tear, rupture, laceration, dislocation or subluxation. The role of the fibular muscles is to evert the ankle and stabilize its subtalar motion (Sinnatamby 2001; Moore, 1999).

The fibular muscles are often stretched and injured from traction during inversion of foot. Therefore, the double slip insertion of fibularis longus muscle into the plantar and lateral surface of base of first metatarsal as observed in the present study may be an additional support for protection against twisting of ankle joint. The insertion of fibularis longus muscle into first dorsal interosseous muscle may increase the potentiality of abduction of second toe and also possibly contribute to accentuate the concavity of foot. Further, the altered the geometry of proximal and distal attachments of peroneus longus muscle may also enhance the stability of talo-calcaneo navicular joint. The present study is a humble attempt to highlight the morphological description of an anomalous disposition of fibular tendons with clinical significance. Awareness of such anatomical variants is important to surgeons undertaking reconstructive procedures.

ACKNOWLEDGEMENT: The authors are thankful to Dr. Hitendra Loh, Assistant Professor in Anatomy for his kind co-operation in photography.

JAYAKUMARI, S.; SURI, R. K.; RATH, G. \& ARORA, J. Tendón accesorio y padrón de inserción trifurcada del músculo fibular largo. Reporte de caso. Int. J. Morphol., 24(4):633-636, 2006.

RESUMEN: Los músculos fibulares son los que evierten el pie y juegan un importante rol en la estabilización de los movimientos subtalares. En el presente caso detectado accidentalmente, reportamos un caso de un tendón accesorio e inserción trifurcado del músculo fibular largo en la pierna izquierda, dos de los cuales estaban fijados en las caras plantar y lateral de la base del primer hueso metatarsiano y el tercero fue encontrado mezclándose con el primer músculo interóseo dorsal. El exacto conocimiento de estas variaciones anatómicas son importantes para los cirujanos en los procedimientos reconstructivos.

PALABRAS CLAVE: Músculo fibular largo; Tendón accesorio; Inserción trifurcada.

\section{REFERENCES}

Bergman, R.A.; Afifi, A.K.\& Ryosuke M. Peroneus Brevis and longus. Illustrated Encyclopedia of Human Anatomic Variation. Opus I. Muscular system, 2005.

Goss, C. CD. Gray's Anatomy. 29 $9^{\text {th }}$ ed. Lea \& Febiger, Philadelphia, 1973.

Harbeson, A. E. The origin of the first dorsal interosseous muscle of the foot J. Anat., 58:116-8, 1933.
Harbeson, A. E. Further studies on the origin of the first dorsal interosseus muscle of the foot from the tendon of the peroneus longus. J. Anat., 72:463-4,1937.

Hecker, P. Study on the peroneus on the tarsus. Anat Rec., 26:79-82,1923.

Henle, J. Handbuch der Muskellehre des Menschen. I. Bd. III. Abt Braunschweig, 1871. pp 298. 
Macalister, A. Observation on muscular anomalies in the human anatomy. Third series with a catalogue of the principal muscular variations hitherto published. Trans. Roy. Irish Acad. (sciences), 25:1, 1875.

Mick, C.A, Lynch,F. Reconstruction of the peroneal retinaculum using the peroneus quartus: A case report. J. of Bone and Joint Surgery [Am], 69A:296-7, 1987.

Moore, K. L.; Arthur, F. \& Dalley. Clinically Oriented Anatomy. $4^{\text {th }}$ ed. Lippincott Williams \& Wilkins A Wolters Kluwer Company, 1999. p 584-5.

Sammarco, G. J. Brainard, B.J. Asymptomatic anomalous peroneus brevis in a high jumper: A case report. J. Bone Joint Surg., 73A:131-3, 1991.

Sinnatamby, C. S. Last'Anatomy Regional and applied. $10^{\text {th }}$. ed. New York, Churchill Livingston, 2001 pp.140-1.

Standring. S. Gray's Anatomy. 39 ${ }^{\text {th }}$ ed. Churchill Livingstone Elsevier New York, 2005. pp 1498-9.

Sobel, M.; Levy, M. E. \& Bohne, W. H.O. Congenital variations of the peroneus quartus muscle: An anatomic study. Foot Ankle, 11:81-9, 1990.

Wachter, S. \& Beekman, S. Peroneus Quartus: A case report. J. Am. Podiatry Med. Assoc., 73:523-4,1983.

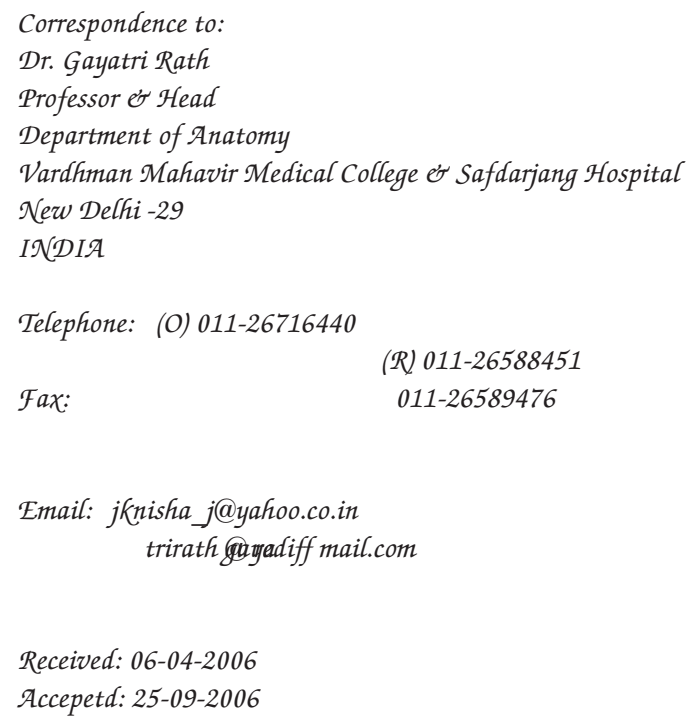

